\title{
PRÁTICAS PEDAGÓGICAS COLABORATIVAS NA ALFABETIZAÇÃO DO ALUNO COM TRANSTORNO DO ESPECTRO AUTISTA
}

\author{
Vera Lucia Messias Fialho Capellini ${ }^{1}$, Priscila Hikaru Shibukawa Shibukawa ${ }^{1}$, Simone Catarina de Oliveira Rinaldo ${ }^{2}$ \\ ${ }^{1}$ Universidade Estadual Paulista - FC-UNESP, Departamento de Educação, Bauru, SP. ${ }^{2}$ Universidade Estadual Paulista-FCLAR-UNESP, \\ Departamento de Pscicologia da Educação, Araraquara, SP.E-mail: verinha@fc.unesp.br
}

\section{RESUMO}

A apropriação do sistema da escrita pelos alunos com Transtorno do Espetro Autista (TEA) é uma forma de facilitar a sua comunicação, dificuldade peculiar do transtorno. Assim, este estudo teve como objetivo investigar e descrever o processo de alfabetização de um aluno com TEA inserido em uma classe comum do ensino regular, observando-se as estratégias utilizadas pelo professor no processo de alfabetização e o apoio colaborativo. Participaram do estudo, uma professora e um aluno com Transtorno do Espectro Autista de uma escola pública municipal do interior paulista. Para a coleta de dados utilizou-se a técnica observacional e uma entrevista inicial e final com a professora. Os resultados mostraram a dificuldade em realizar as intervenções de maneira colaborativa. Porém, pôde-se constatar um avanço no desenvolvimento da linguagem escrita pelo aluno autista. Conclui-se que a credibilidade na aprendizagem do aluno com TEA é o primeiro passo para a sua alfabetização e letramento, sendo necessário o trabalho colaborativo entre educação especial e ensino comum.

Palavras-chave: Alfabetização, Transtorno do Espectro Autista, Autismo, Ensino Colaborativo, Inclusão Escolar.

\section{COLLABORATIVE EDUCATIONAL PRACTICES IN LITERACY A STUDENT WITH AUTISM SPECTRUM DISORDER.}

\section{ABSTRACT}

The appropriation of the writing system by students with Autistic Spectrum Disorder (ASD) is a way to facilitate their communication, peculiar difficulty disorder. This study aimed to investigate and describe the literacy process of a student with ASD inserted into a common class of mainstream education, observing the strategies used by the teacher in the literacy process and collaborative support. They participated in the study, a teacher and a student with Autism Spectrum Disorder a public school in São Paulo. For data collection was used the observational technique and initial and final interview with the teacher. The results show the difficulty in performing interventions collaboratively. However, it could be seen a breakthrough in the development of written language by autistic student. It concludes that the credibility on student learning with ASD is the first step in its literacy and literacy, requiring collaborative work between special education and regular education.

Keywords: Literacy, Autism Spectrum Disorder, Autism, Collaborative Education, School Inclusion.

\section{A. INTRODUÇÃO}

O processo de alfabetização e letramento é essencial para que o sujeito consiga interagir na sociedade, isso porque o código linguístico se constitui de signos arbitrários convencionados socialmente, utilizados para transmitir uma ideia ou um ponto de vista, desenvolvendo comportamentos e habilidades de uso competente da leitura e da escrita em práticas sociais. Assim, é por meio da alfabetização e do letramento que o sujeito se torna capaz de perceber e compreender as mais diversas situações de interação que ocorrem na sociedade, conseguindo analisar crítica e reflexivamente a sua realidade, bem como modificá-la (SOARES, 2000).
E neste processo de alfabetização, cada criança aprende de uma forma diferente, sendo que este também se aplica às pessoas com deficiências. Elas aprendem de acordo com suas singularidades, ou seja, cada criança apresenta características próprias como resposta ao processo ensino-aprendizagem. Dessa forma, as diferentes deficiências exigem práticas pedagógicas especiais próprias, de acordo com suas necessidades e potencialidades. Este também é o caso de criança com Transtorno do Espectro Autista (TEA), foco deste estudo.

O autismo ou TEA é uma condição que foi descrita, inicialmente, na década de 1940, mas, ainda hoje, intriga profissionais de diversas áreas, bem como a população de maneira geral. Isto se 
deve ao fato, provavelmente, da diversidade encontrada entre as pessoas com este diagnóstico e da multiplicidade de dúvidas em relação à causa e a forma de intervir nos diferentes casos.

Caracterizado pelas dificuldades nas interações sociais e na comunicação, além de apresentar um repertório restrito de atividades e interesses, as manifestações do TEA variam de acordo com a idade e a fase de desenvolvimento da criança. Os prejuízos nas interações sociais envolvem o comportamento não verbal, especialmente aqueles relacionados ao contato visual direto, as expressões faciais e corporais. $\mathrm{Na}$ comunicação, poderá afetar tanto as habilidades verbais quanto as não verbais, podendo comprometer o desenvolvimento da linguagem falada e quando falam, podem apresentar dificuldades para manter uma conversação (BRASIL, 2010).

Quando a fala se desenvolve, o timbre, a entonação, a velocidade, o ritmo ou a ênfase podem ser anormais. As estruturas gramaticais são frequentemente imaturas e incluem o uso estereotipado e repetitivo. Pode-se observar uma perturbação na capacidade de compreensão da linguagem, como entender perguntas, orientações ou piadas simples (BRASIL, 2010, p.15).

As crianças com TEA apresentam ainda prejuízos acentuados na capacidade imaginativa e, com frequência, interessam-se por rotinas ou rituais não funcionais. Assim, poderão apresentar movimentos corporais (todo o corpo) ou envolvendo as mãos de forma estereotipada, além de posturas inadequadas. Podem apresentar, ainda, um interesse persistente em determinados objetos ou em parte de deles, especialmente, aqueles com movimentos giratórios (BRASIL, 2010).

Esta tríade de comprometimentos interação social, comportamento e comunicação - podem acarretar algumas limitações no processo de aprendizagem do aluno com TEA. No entanto, sua escolarização é possível, quando the são oferecidas as oportunidades de acordo com suas necessidades e potencialidades, a partir de uma perspectiva da educação inclusiva.
No Brasil, as pesquisas sobre a inclusão escolar de crianças com TEA no sistema regular de ensino estão se intensificando, assim como as investigações sobre os processos de alfabetização e letramento de tais alunos. Entretanto, ainda há uma dissociação em relação às discussões sobre esses dois aspectos supracitados.

Capellini (2004) e Omote (2008) apontam a necessidade de se investigar o desempenho também acadêmico de alunos com deficiência e não somente as concepções de professores acerca do processo, assim como promover uma reflexão sobre a socialização destes alunos, sobretudo daqueles com autismo e sua alfabetização.

É importante ressaltar que, assim como a linguagem oral, o processo de alfabetização e letramento é essencial para a consolidação das relações interpessoais, especialmente para os alunos com TEA. É necessário que sejam estimuladas suas habilidades de comunicação e expressão, para que consigam interagir socialmente e compreender a sua realidade e agir sobre ela, minimizando, dessa forma, as barreiras trazidas pelo transtorno.

Dessa maneira, principalmente nas séries iniciais do ensino fundamental, o aluno com TEA precisa de um ensino direcionado, que consiga auxiliá-lo na interiorização da linguagem social e exteriorização do pensamento, de modo a assimilar os signos arbitrários convencionados socialmente e usá-los de modo intencional e autônomo. É em busca dessas especificidades que este estudo se faz relevante.

Em suma, este estudo visou investigar e descrever o processo de alfabetização e letramento de um aluno com TEA inserido em uma classe comum do ensino regular.

\section{B. MÉTODOS}

Este estudo é pautado numa metodologia qualitativa de natureza interventiva. De acordo com Bogdan e Biklen (1994), os estudos qualitativos assumem diferentes significados na área da educação e visam à descrição e decodificação dos sentidos atribuídos pelos participantes. Nesse sentido, poderão ser utilizadas variadas técnicas para a coleta dos dados como: entrevistas não estruturadas ou semiestruturadas, a observação participante, bem como os grupos focais. Neste estudo, utilizamos a técnica observacional e a entrevista.

Já os estudos de natureza interventiva visam à busca de resoluções para os problemas 
ou para situações que se apresentem como insatisfatórias, em que há um envolvimento entre o pesquisador e os participantes, promovendo, dessa forma, mudanças significativas (CHIZZOTTI, 2003) o que vai ao encontro de nossos objetivos.

Participaram deste estudo uma professora de classe comum e um aluno com diagnóstico médico de TEA, de uma Escola do interior do estado de São Paulo.

Os dados foram coletados a partir da observação participante e das intervenções realizadas, bem como de entrevista com a professora da classe comum, de acordo com as seguintes etapas:

a) as observações e intervenções ocorreram durante dois bimestres (fevereiro-junho), três vezes por semana, visando identificar as práticas de inclusão e de alfabetização em sala de aula. Além das observações, neste período, foi realizada uma intervenção, apoiando colaborativamente a professora, auxiliando no planejamento e no desenvolvimento de práticas pedagógicas relacionadas à alfabetização para o aluno com autismo. Todas as informações coletadas durante este período foram registradas em um diário de campo, para análises posteriores;

b) antes e após este período de observação e intervenção foram realizadas duas entrevistas com a professora do aluno, uma inicial que teve como objetivo analisar a sua visão com relação à política de inclusão escolar, bem como os seus conhecimentos a respeito desse tipo de deficiência, e outra, ao final, visando a uma avaliação do desempenho escolar do aluno, bem como analisar e comparar os resultados das observações e da intervenção colaborativa com os dados da entrevista.

Os dados foram analisados e descritos qualitativamente, de acordo com a "análise de conteúdo" de Bardin (2009). A análise do conteúdo permite a atribuição de relevância aos comentários diretos extraídos das aulas e das entrevistas, considerando-se as palavras empregadas e os seus significados, o contexto em que foram colocadas as ideias, a frequência, a extensão dos comentários e a especificidade das respostas.

Para a análise, foram selecionados alguns episódios que contemplam o objeto de estudo, os registros do diário de campo e as entrevistas com a professora, agrupando-os em categorias de acordo com similaridade ou recorrência, pertinência e relevância para exame.
As produções do aluno foram analisadas, estabelecendo-se um comparativo entre seu desempenho antes e depois da intervenção, observando se houve avanços, retrocessos ou manteve-se inalterado o desenvolvimento escolar do aluno com relação, especificamente, ao processo de alfabetização e letramento.

\section{RESULTADOS}

Para a apresentação dos resultados, dividiu-se a análise dos dados em três categorias: relações interpessoais do aluno com o outro (professor, pesquisadora e demais alunos); desafios do professor com relação à inclusão e ao processo de alfabetização e letramento; processo de intervenção e suas contribuições para o desenvolvimento da linguagem escrita.

\section{Categoria 1 - relações interpessoais do aluno com os demais (pesquisadora, professora e alunos)}

As observações tiveram início no começo do ano letivo, o que favoreceu o estabelecimento do vínculo do aluno com a pesquisadora e com a professora. Segundo Gauderer (1997), uma das principais barreiras para o processo de aprendizagem está relacionada às interações do aluno com autismo com os demais ao seu redor.

Inicialmente, o aluno não interagia, permanecendo sentado na cadeira, ou movimentando-se pela sala o tempo todo ou, ainda, brincando sozinho, e, raras vezes, copiava o que estava na lousa. À medida que o vínculo se fortalecia, observou-se que o aluno se sentia mais confortável para fazer questionamentos sobre os conteúdos, e sua participação tornava-se mais significativa naquele espaço.

Desde a primeira semana de observação, foi possível notar que a professora tratava o aluno de maneira diferenciada em relação aos demais, tanto no que se refere aos conteúdos, quanto em relação ao tratamento pessoal e, até mesmo, a linguagem era diferenciada, infantilizada. Tal fato pode ser sentido como falta de credibilidade no potencial do aluno, tratandoo de forma desigual, privado-o de seu direito de ser tratado com igualdade, como retrata a Constituição Federal Brasileira (BRASIL, 1988).

Durante todo o período de observação e apoio colaborativo junto à professora, notou-se que esta assumia uma postura de distinção no tratamento e ensino ao aluno com autismo, o que, consequentemente, dificultava o seu 
desenvolvimento tanto da escrita e letramento como nas relações com os demais.

$\mathrm{Na}$ entrevista inicial, a professora ressalta que está cada vez mais difícil ensinar aos alunos, tendo em vista a mudança sócio-cultural ocorrida na sociedade durante esses mais de 20 anos em que leciona, conforme se visualizava em seu discurso.

"No meu tempo de magistério não tinha essas teorias aí, construtivismo, essas coisas. Era só a cartilha, que eu ainda acho bem melhor, porque antes o pessoal aprendia, respeitava a professora, hoje ta cada dia mais difícil, você vê aí, tem muito aluno nessa sala desinteressado, que não quer nada da vida. Aí falam que você não pode mais usar a cartilha, que tem que dar textos na aula, eu tento, faço minha parte, mas às vezes parece que não dá certo."

É importante esclarecer que esta é a primeira experiência da professora com alunos com deficiência em sua sala de aula. Há dois alunos autistas (um menino e uma menina) sendo a menina, portadora da Síndrome de Asperger, atualmente, também inserida no Quadro do Autismo. Deve-se levar em consideração a formação da professora, que cursou apenas o Magistério, não se sentindo preparada para a atuação com crianças que precisam de uma atenção pedagógica diferenciada.

Seu discurso é evidenciado em vários episódios, como, por exemplo, enquanto os demais alunos faziam atividades de escrita de palavras ou de leitura, entregava ao aluno com autismo uma cópia de um livro de gravuras, visando entretê-lo com pinturas. Assim, as adaptações realizadas consistiam em facilitar a atividade, e não fazer com que o aluno pudesse realizar a mesma atividade que os demais, por meio de recursos e estratégias diferenciadas.

A própria professora, durante a entrevista, afirma não saber lidar com tais alunos, devido à sua formação.

"Acho que o Estado deveria dar um curso pra gente saber como trabalhar com esses alunos, porque eu fiz magistério já tem muito tempo e na minha época não tinha essas coisas. [...] Falam que a gente tem que incluir os alunos e que todo mundo tem que aprender as mesmas coisas, mas você vê, eles não conseguem acompanhar."

Tal discurso retrata o descontentamento com as políticas voltadas para a inclusão escolar e o despreparo pedagógico em relação aos alunos com deficiência. Observa-se que a própria docente não acredita na sua potencialidade e no seu papel enquanto educadora, no sentido de criar condições e estratégias para que a aprendizagem realmente se efetive.

Com relação às interações do aluno com autismo com os demais, observou-se que, praticamente, metade deles já havia convivido no ano anterior, mas eram bem poucos aqueles que procuravam relacionar-se com 0 aluno com autismo, mantendo-o, quase sempre, à margem.

A educação inclusiva de pessoas com deficiência, transtornos globais do desenvolvimento e altas habilidades/superdotação, remete-nos a perspectiva de garantia de oferta de uma escolarização qualificada que garanta o aprendizado e sucesso acadêmico dos alunos matriculados no ensino comum. A sua escolarização impõe uma nova configuração no espaço escolar e no desenvolvimento do trabalho pedagógico inclusivo. As condições de ensino devem ser modificadas para atender as necessidades dos educandos, desde a infraestrutura até as estratégias utilizadas em sala de aula (OMOTE, 2011). Para Capellini e Rodrigues (2009), a inclusão implica em muitas mudanças na escola (currículo, avaliação, formação da equipe), e na política educacional.

Dessa forma, para que a educação do aluno com TEA seja significativa, promovendo sua socialização e comunicação, o processo de alfabetização e letramento caracteriza-se como um aspecto fundamental. O professor deverá buscar conhecimentos, estratégias e recursos diferenciados para tornar sua prática pedagógica mais inclusiva, favorecendo ao aluno uma aprendizagem de efetiva qualidade.

$\mathrm{Na}$ entrevista inicial, a professora alega não ter concluído o curso de licenciatura em pedagogia, tendo cursado apenas o magistério (ensino médio). Esse dado coloca em pauta a questão da qualidade da formação do professor tanto para o processo de alfabetização e 
letramento, quanto para atuar com alunos com deficiência.

Desde as primeiras observações, nota-se uma prática tradicional, ou seja, aquela que corresponde a uma educação bancária (domesticadora), como ressalta Freire (1981). Nesta metodologia pedagógica, o sujeito torna-se um mero receptor passivo de informações que Ihe são depositadas por outros.

Logo no primeiro dia de aula, a professora inicia seu discurso com as regras, sendo que uma delas é a de que não se pode conversar durante a aula, só quando a professora permitir. Escreve o cabeçalho na lousa e solicita que os alunos copiem e informa que, após, ela fará a verificação se está certo. Os alunos obedecem, sem questionar, permanecendo em silêncio.

Nesse episódio, nota-se que a função da escola está sendo a de domesticar os alunos, não permitindo que interajam entre si, inibe-os de fazer questionamentos e os coloca em posição de depósito de conhecimentos.

Esse processo de escolarização, segundo Freire (1981), debilita o potencial humano, quando a educação deveria estimular a libertação da consciência para o desenvolvimento da potencialidade criativa e emancipação do sujeito social.

A professora relata que, no ano anterior, havia lecionado no 20 ano, e afirma que, às vezes, ficava nas aulas de educação física e de artes com um ou dois alunos, no fundo da sala fazendo exercícios da cartilha "Caminho Suave", que guarda em seu armário. A justificativa para adotar tais práticas é a de que "tem alunos que não conseguem aprender com os métodos diferentes, tem que copiar várias vezes, que daí entra na cabecinha deles"

A docente ressalta ainda que mantém guardado o caderno de registros das atividades do ano anterior, o que facilita quando precisa fazer cópias para a classe atual. De fato, isso ocorria na maioria dos dias letivos que foram observados: a professora levava cópia-xerox das atividades, as quais consistiam sempre em pintar a figura e após o aluno deveria realizar o que era solicitado, como ligar os pontos, escrever os nomes dos bichos dentro do espaço em branco, preencher o calendário, pintar as letras solicitadas, entre outras atividades descontextualizadas.

Também se utilizava de cartazes, os quais consistiam em cantigas de roda, cantigas populares, parlendas e listas diversas. No entanto, tais cartazes eram utilizados como meios de treinar a leitura, não havia contextualização, explicação das origens ou interpretação do porquê da escrita, caracterizando um ato mecânico de leitura, ou seja, realizava apenas a decodificação das letras.

Em alguns momentos, em razão das conversas paralelas daqueles que concluíam a atividade mais rapidamente, a professora acelerava os conteúdos, sendo que a maioria não conseguia acompanhar o novo ritmo.

"Eu sei que tem alunos que não estão acompanhando, que são mais fraquinhos, mas tem uns que são muito bons, eles são rapidinhos, e fazem muita bagunça, então tenho que manter eles ocupados, né?! Não dá pra deixar eles parados, eles começam a conversar e vira a maior bagunça."

Nestes relatos, observa-se o resultado da falta de conhecimentos pedagógicos e didáticos atualizados, permanecendo uma prática obsoleta, sem perspectivas de uma educação para a vida, para a emancipação do cidadão.

Pode-se dizer que tal discurso decorre, provavelmente, da defasagem da formação inicial e continuada da docente, a qual ainda carrega, intrinsecamente, práticas pedagógicas baseadas no modelo tradicional.

Nesse sentido, o processo de alfabetização e letramento de todos os alunos, e não somente do aluno com autismo, encontravase prejudicado, desmotivando a todos. Sem práticas diferenciadas, a docente buscava ensinar a todos de uma mesma maneira, sem repensar meios de potencializar a aprendizagem de todos seus alunos, o que contraria os princípios contidos na Política Nacional de Educação Especial na Perspectiva da Educação Inclusiva (BRASIL, 2008).

O desconhecimento sobre as especificidades do autismo, bem como o de práticas alternativas para alfabetizar e letrar esse aluno, impedem que a professora intervenha significativamente nesse processo.

$\mathrm{Na}$ entrevista final, observa-se uma pequena mudança em seu discurso em relação à concepção de autismo, acreditando que a inclusão do aluno está sendo boa, mostra-se mais sensibilizada com a questão da inclusão de alunos 
com deficiência. Também evidencia o início da percepção sobre as práticas alternativas de alfabetização e letramento, relatando, que o aluno "está aprendendo bastante, porque do jeito tradicional ele não estava conseguindo. Cheguei a pensar que ele não ia aprender nada, estava ficando desesperada."

A análise das questões sobre a leitura e a escrita está fundamentalmente relacionada à concepção que se tem sobre o que é a linguagem e o que é ensinar e aprender. E essas concepções passam, obrigatoriamente, pelos objetivos que se atribuem à escola e à escolarização.

Nesse sentido, a alfabetização e o letramento são dois processos distintos, mas, extremamente interligados e dialéticos, ou seja, deve existir uma articulação entre estes dois processos, para que a alfabetização possa ocorrer, de modo contextualizado com a realidade significativa. Este processo tem fundamental importância na integração efetiva e significativa dos alunos com TEA na sociedade. Isso decorre da possibilidade de diminuir as barreiras impostas pela deficiência, tendo em vista que a alfabetização e o letramento garantiriam mais uma forma de comunicação e expressão social, já que as suas habilidades da linguagem oral poderão estar comprometidas. Assim, se proporcionaria ao aluno a oportunidade de tornar-se mais autônomo, à medida que desenvolvesse mais uma forma de interação com o mundo externo.

Tal contexto traz uma situação inédita e desafiadora para as escolas brasileiras de ensino regular, pois, ao mesmo tempo em que devem acolher a todos os alunos, precisam oferecer-lhes um aprendizado de qualidade real, como ressalta Freitas (2006, p. 166):

A educação das necessidades educacionais especiais, no contexto do ensino regular, permite, tanto aos professores já atuantes quanto aos que estão em formação, rever os referenciais teóricometodológicos que se alicerçaram na distinção entre educação especial e geral, uma vez que [...] a educação dos alunos com necessidades educacionais têm os mesmos objetivos da educação de qualquer cidadão. [...] Incluir e garantir uma educação de qualidade para todos é, hoje, o fator mais importante na redefinição dos currículos escolares, desafiando a coragem das escolas em assumir um sistema educacional 'especial' para todos os alunos.

Para tanto, é fundamental que as escolas aprimorem suas ações pedagógicas, visando ao atendimento das diferenças. Nesse sentido, é imprescindível a transformação desta, na busca de alternativas metodológicas que proporcionem um ensino de qualidade. Mudar a escola exige trabalho de todos os envolvidos no processo, e assim, é preciso colocar a aprendizagem como eixo norteador das práticas educativas inclusivas, para que os alunos possam aprender a partir de suas necessidades e potencialidades.

Dessa forma, a inclusão escolar é uma proposta educativa que se estabelece a partir das políticas educacionais voltadas para a implementação de um novo paradigma de educação, no qual a "educação especial" deveria se configurar por um processo escolar/acadêmico, que vai do ensino básico ao superior.

Categoria 3 - processo de intervenção e suas contribuições para 0 desenvolvimento da linguagem escrita.

No início do processo de alfabetização, o aluno não distinguia letras de números. $E$, no início das aulas, o aluno com autismo, recebera da professora uma tabela com o alfabeto ilustrado, tendo como tarefa, fazer a leitura todos os dias, em casa e na escola. Dessa forma, o aluno apenas memorizou o alfabeto, constituindo uma ideia equivocada dos signos do alfabeto e sua representação.

Assim, durante o processo de intervenção (apoio colaborativo), foi preciso desconstruir essa ideia inicial, para depois conseguir fazê-lo compreender o sistema da escrita, o qual é composto por signos arbitrários e é convencionado socialmente. Tal desconstrução foi realizada durante as aulas, principalmente por meio da escrita do próprio nome, sendo que ao escrever seu nome, o aluno conseguia observar que era preciso mais letras do que apenas a primeira de seu nome. Ele revelou-se extremamente esforçado, podendo-se dizer que, algumas vezes, chegava a um caso de 
perfeccionismo. Escrevia as letras de forma, calculando milimetricamente para caberem exatamente no espaço entre as linhas. Ao final, foi possível observar uma diferença significativa no processo de aprendizagem e letramento do aluno. A partir da sua realidade (seu nome) apresentou respostas satisfatórias ao trabalho desenvolvido.

\section{DISCUSSÃO}

Diante das atividades propostas pela pesquisadora, como contação de histórias, álbum de fotografias, pode-se dizer que o processo de alfabetização e letramento ocorreu, de modo que a linguagem escrita fora utilizada com vistas a um alcance social, pois à medida que o aluno aprendia os nomes dos demais colegas da sala, favorecia a criação de vínculos, aumentando seu círculo de amizades. Para ele, o processo de alfabetização e letramento mostrou-se essencial para que a interação social com os demais alunos da sala fosse potencializada.

Durante os dois bimestres, observou-se uma evolução significativa do aluno em relação à aprendizagem e ao comportamento. A própria professora mostrou-se satisfeita com o apoio recebido, ressaltando na entrevista final:

"Não esperava que fosse dar certo, imaginava que sei lá, ele pudesse aprender a escrever algumas coisas assim... Mas o nome de uns alunos, né, e da mãe, e do pai também... Nossa nem imaginava. Fico feliz, porque assim, no começo achei que não ia dar pra ele aprender nada assim mais difícil, só assim... bola, gato, sabe?! Palavras mais fáceis".

O avanço no desenvolvimento da linguagem escrita do aluno foi evidenciado a princípio pela distinção de números e letras, refletindo a internalização dos signos linguísticos, demonstrando conhecimento sobre sua funcionalidade para a escrita. Outro aspecto a ser destacado é que o aluno começou a ler e escrever palavras com sílabas simples (algumas famílias silábicas que estavam no álbum) e também algumas com sílabas complexas, aquelas pertencentes ao seu cotidiano (nome dos pais, do irmão, da professora, da pesquisadora). Esse aprendizado ocorreu em um espaço de tempo relativamente curto, sendo que, possivelmente, deve-se a uma das características do autismo, ou seja, à "capacidade surpreendente de alguns em memorizar grande quantidade de material que Ihe seja interessante" (BRASIL, 2010, p. 09).

$\mathrm{O}$ aluno passou a ser incluído em algumas atividades realizadas pelo restante da sala, das quais, antes, era totalmente marginalizado, além de conseguir reconhecer mais colegas de sala por meio do álbum de fotografia, fato esse que auxiliou no processo de interação e inclusão aos demais na sala de aula.

Em síntese, o estudo mostrou a possibilidade da alfabetização do aluno com autismo e da sua inclusão na classe comum, mas evidenciou, também, a dificuldade na implementação da colaboração com a professora da classe comum, demandando maiores estudos sobre esta parceria prevista na Política de Educação Especial na Perspectiva da Educação Inclusiva.

Por meio da metodologia adotada nessa pesquisa, foi possível, além de observar e descrever o contexto do processo de alfabetização e letramento de um aluno com autismo, também realizar intervenções pedagógicas com o aluno, potencializando sua aprendizagem, notando-se considerável desenvolvimento das linguagens escrita e oral. Isso ocorreu tendo em vista a dialogicidade entre a fala e a escrita.

Tendo isso posto, avalia-se que, apesar das limitações geradas pela deficiência, não se pode deixar de acreditar no potencial do aluno; deve-se, em contrapartida, fazer com que o aluno se desenvolva por meio de práticas pedagógicas alternativas e diferenciadas, que favoreçam sua aprendizagem de maneira adequada e com qualidade no ensino.

\section{REFERÊNCIAS}

BARDIN, L. Análise de conteúdo. Lisboa: Edições 70, 2009.

BRASIL. Ministério da Educação. Educação especial na perspectiva da inclusão escolar: transtornos globais do desenvolvimento. Brasília: MEC, 2010.

BRASIL. Resolução n. 4, de 2 de outubro de 2009, que institui diretrizes operacionais para o atendimento educacional especializado na educação básica, modalidade educação especial. Brasília: CNE/CEB, 2009.

BRASIL. Ministério da Educação. Secretaria de Educação Especial. Política Nacional de 
Educação Especial na Perspectiva da Educação Inclusiva. Brasília: Ministério da Educação, 2008. BRASIL. Constituição da Republica Federativa do Brasil. Brasília: Imprensa Oficial, 1988.

BOGDAN, R. C.; BIKLEN, S. K. Investigação qualitativa em educação. Porto: Porto Ed., 1994. $335 \mathrm{p}$.

CAPELLINI, V. L. M. F.; RODRIGUES, O. M. P. R. Concepções de professores acerca dos fatores que dificultam o processo da educação inclusiva. Educação, Porto Alegre, v. 32, n. 3, p. 355-364. 2009.

CAPELLINI, V. L. M. F. Avaliação das possibilidades do ensino colaborativo no processo de inclusão escolar do aluno com deficiência mental. 2004. 300 f. Tese (Doutorado em Educação Especial) - Programa de PósGraduação em Educação Especial, Universidade Federal de São Carlos, São Carlos, SP.

CHIZZOTTI, A. Pesquisa em ciências humanas e sociais. São Paulo: Cortez, 2003.

FREIRE, P. A pedagogia do oprimido. Rio de Janeiro: Paz e Terra, 1981.

FREITAS, S. N. A formação de professores na Educação inclusiva: construindo a base de todo o processo. In: RODRIGUES, D. (Org.). Inclusão e educação: doze olhares sobre a educação inclusiva. São Paulo: Summus, 2006. p. 161-181.

GAUDERER, C. Autismo e outros atrasos do desenvolvimento - guia prático para pais e profissionais. São Paulo: Revinter, 1997.

NILSSON, I. A educação de pessoas com desordens do espectro autístico e dificuldades semelhantes de aprendizagem. Temas sobre desenvolvimento, v. 12, n. 68, p. 5-45, 2003.

SOARES, M. B. Letrar é mais que alfabetizar. Jornal do Brasil,26 nov. 2000.

OMOTE, S. Diversidade, educação e sociedade inclusiva. In: OLIVEIRA, A. A. S.; OMOTE, S.; GIROTO, C. R. M. Inclusão escolar: as contribuições da educação especial, SãoPaulo: Cultura Acadêmica Editora, Marília: Fundepe Editora, 2011. p. 15-32.

OMOTE, S. Diversidade, educação e sociedade inclusiva. In: OLIVEIRA, A. A. S.; OMOTE, S.; GIROTO, C. R. M. (Org.). Inclusão escolar: as contribuições da educação especial. São Paulo: Cultural Acadêmica, Marília: Fundepe, 2008, p. 15-32.
Recebido para publicação em 06/07/2015

Revisado em 15/10/2015

Aceito em 23/02/2016 